Ethos : Jurnal Penelitian dan Pengabdian kepada Masyarakat, Vol 7, No.1, Januari 2019: 46-55

\title{
Pelatihan Customer Service Excellence PADA KaRYAWAN RSCM KIRANA
}

\author{
${ }^{1}$ Gracia Rachmi Adiarsi, ${ }^{2}$ Rani Chandra Oktaviani \\ 1, 2 Jurusan Ilmu Komunikasi, STIKOM London School of Public Reralations (LSPR) Jakarta \\ E-mail: ${ }^{1}$ gracia.ra@lspr.edu; ${ }^{2}$ rani.co@lspr.edu
}

\begin{abstract}
All institutions that seek profit or non-profit, either service or product companies feel important in establishing cooperation and communication with customers. One health care institution, RSCM Kirana Jakarta eye health hospital, considers it important and urgent to conduct good service training for customers considering the competition in the field of health services. From the observations and discussions review with RSCM Kirana, this community service was carried out in the form of customer service excellence training to a number of employees and divisions related to the implementation of services. The implementation of the training combines the concept of "customer service excellence" and training practices. This training can change the level of confidence and skills in providing services by employees based on the results of the pre-test and post-test evaluations. Evaluations come from the trainers and representative of employees. The recommendation for management that should conduct customer service excellence training before employees will be placed in the customer service position. This is useful for providing employees with knowledge and skills in serving customers.
\end{abstract}

Keywords: Customer Service, Communication, Training.

\begin{abstract}
Abstrak. Semua institusi baik itu institusi profit maupun non-profit, baik perusahaan jasa atau produk merasa penting dalam menjalin kerjasama dan komunikasi dengan customer. Salah satu institusi jasa kesehatan yaitu RSCM Kirana Jakarta rumah sakit kesehatan mata menganggap penting dan mendesak (urgent) untuk melakukan pelatihan layanan yang baik terhadap customer mengingat persaingan di bidang layanan kesehatan. Dari hasil observasi dan diskusi dengan pihak RSCM Kirana maka pengabdian masyarakat ini dilakukan dalam bentuk pelatihan customer service excellence kepada sejumlah karyawan dan divisi yang berkaitan dengan pelaksanaan jasa pelayanan. Pelaksanaan pelatihan mengkombinasikan konsep "customer service excelence" dan praktik pelatihan. Berdasarkan hasil evaluasi pre-test dan post-test dari tim pelatih serta evaluasi dari perwakilan manajemen karyawan RSCM Kirana, pelatihan ini dapat merubah tingkat kepercayaan diri dan keterampilan dalam memberikan layanan oleh karyawan RSCM Kirana Jakarta. Adapun rekomendasi bagi pihak manajemen ialah sebelum karyawan ditempatkan pada posisi layanan customer sebaiknya dilakukan pelatihan customer service excellence terlebih dahulu. Hal ini berguna untuk membekali karyawan tentang pengetahuan dan ketrampilan dalam melayani customer.
\end{abstract}

Kata kunci: Customer Service, Komunikasi, Pelatihan.

\section{Pendahuluan}

Suatu layanan prima dibutuhkan disetiap organisasi baik organisasi profit maupun non-profit. Institusi kesehatan yang memberikan layanan kepada pasien untuk melakukan pengobatan suatu penyakit baik yang dimiliki pemerintah maupun swasta saling berkompetisi untuk merebut pasien. Salah satu 
Rumah Sakit yang dimiliki pemerintah yaitu Rumah Sakit Umum Pusat Nasional Dr. Cipto Mangunkusumo pada tahun 2013 meresmikan Unit Pelayanan Terpadu Kesehatan (UPTK) Mata RSCM Kirana Jakarta yang memiliki visi menjadi pusat Oftamologi terbaik di Indonesia sekaligus menjadi layanan kesehatan mata terbaik di Asia Pasifik (http://www.pdpersi.co.id/content/news. php? catid=2\&mid=5\&nid=1261).

Selain itu kebutuan pelayanan prima yang merupakan bagian dari visi dan misi rumah sakait, berpegang pada pelayanan prima seperti meninjau penelitian sebelumnya yang menyatakan bahwa:

"Masalah kesehatan merupakan masalah sangat penting maka upaya untuk melakukan pengobatan dalam wujud layanan prima (service excellent) dengan layanan cepat harus dilakukan sehingga tidak muncul banyak keluhan. Memaksimalkan layanan prima rumah sakit di Indonesia menjadikan penurunan intensi pasien Indonesia berobat ke luar negeri" (Dhuhaniyati, 2012).

Pentingnya dilakukan pelatihan ini karna pelayanan prima bagian dari pelayanan yang disayaratkan oleh badan akreditasi rumah sakit, persyaratan tersebut bagian dari 12 aspek yang perlu di lakukan dengan baik oleh rumah sakit seperti terjabar sebagai berikut : 1) Pelayanan administrasi manajemen, pelayanan medis, pelayanan keperawatan, pelayanan rekam medis, pelayanan gawat darurat, pelayanan K3, pelayanan farmasi, pelayanan perinatal resiko tinggi, pengedalian infeksi nosokamial, pelayanan lab, pelayanan radiologi dan pelayanan kamar operasi. Tentunya semua ini, akan berjalan dengan baik dengan personil yang memahami standard pelayanan (Kuntjoro, 2007).

Pada dasarnya pelayanan pada rumah sakit atau pelayanan kesehatan dapat dijabarkan menjadi 2 aspe yakni dimensi teknis dan dimensi fungsional. Pelayanan teknis didefiniskan sebagai pelayanan akusasi medis dalam mendiagnosa dan bentuk prosedur. Sedangkan fungsional lebih kepada bentuk pelayanan (service) yang diberikan kepada pasien (Health care service quality: A comparison of public and private hospitals, 2010).

Untuk mencapai visi tersebut RSCM Kirana melakukan berbagai upaya agar pasien mendapatkan layanan yang prima yang meliputi medis dan non medis seperti komunikasi. Pengalaman pasien dan keluarga pasien dapat dianggap sebagai serangkaian proses perawatan kesehatan yang relatif rumit mulai dari masuk halaman parkir, meja pendaftaran, berkomunikasi dengan dokter dan juga suster, berurusan dengan apotik dan lainnya. Semua melibatkan layanan yang diberikan oleh institusi kesehatan dalam hal ini Rumah Sakit kepada pasiennya.

Sebelum dilaksanakannya pengabdian masyarakat ini, dilakukan diskusi dengan pihak RSCM Kirana, dari hasil diskusi didapat beberapa topik permasalahan yang dihadapi oleh Mitra sbb:

Beberapa karyawan belum mampu memberikan pelayanan dari aspek komunikasi yang baik kepada pasien atau keluarga pasien, baik secara komunikasi verbal maupun non-verbal.

Adanya beberapa layer karyawan dan divisi yang terlibat dalam komunikasi pelayanan mulai dari security hingga beberapa divisi front liner, membuat cara berkomunikasi berbeda. 
Karena adanya perbedaan level, terkadang pada saat perekrutan belum diberikan pelatihan customer service, kepada karyawan.

Identifikasi kurangnya kepercayaan diri karyawan dalam berkomunikasi, terlebih jika harus menangani komplain dari pasien atau keluarga pasien.

Pada beberapa kasus, pelayanan dinilai buruk karena kebiasaan dan karakter pribadi karyawan, seperti cuek, minder, atau bahkan tidak komunikatif.

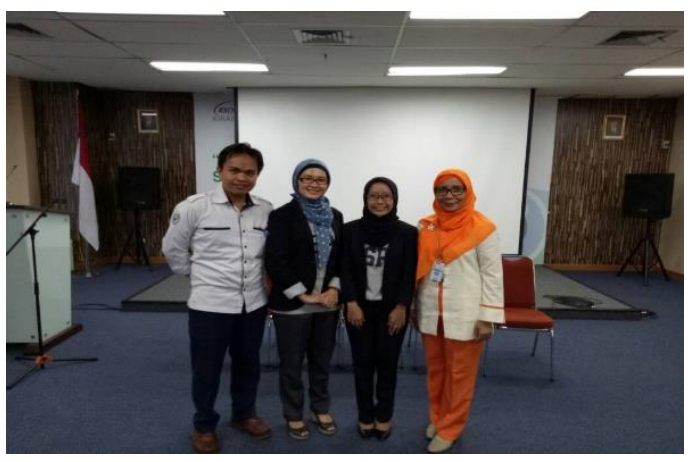

Gambar 1. Diskusi Masalah dengan Menajemen RSCM Kirana terkait

Dari analisis permasalahan yang didapat pada awal pengabdian masyarakat ini, maka diputuskan dan disepakati bahwa perlunya pelatihan kepada karyawan RSCM Kirana. Pelatihan dilakukan dengan memberikan materi dan tips keterampilan berkomunikasi efektif dalam memberikan layanan prima, serta praktik dan role play untuk membangkitkan rasa percaya diri.

Sehingga pelatihan dibuatlah dua materi, yang pertama adalah modul materi pengajaran yang lebih banyak diambil dari beberapa literatur dalam menangai pelayangan prima beberapa konsep komunikasi di ambil dalam sumber materi dibawah ini:

Carlzon (1987) mengemukakan adanya moment of truth (momen kebenaran) yang terbentuk di benak customer akan organisasi yang melaksanakan layanan kepada customer. Dalam hal ini kualitas layanan dari institusi kesehatan seperti RSCM Kirana dapat berdampak tindakan si pasien atau keluarganya apakah mereka akan kembali atau merekomendasikan RS tersebut kepada saudara atau temanteman mereka.

Zeithaml dkk (1990) mengemukakan model konseptual kualitas layanan yang membandingkan persepsi customer yang terbentuk selama atau mendapat layanan dengan harapan. Jika persepsi customer merasa tidak terpenuhi harapannya maka yang terjadi kekecewaan atau suatu gap negatif. Kesenjangan inilah yang harus diantisipasi oleh Rumah Sakit (RS) dalam melayani pasien. RS sebagai organisasi harus memahami, merancang dan mengembangkan standar layanan kepada pasien.

Untuk memberikan layanan prima kepada customer RSCM Kirana maka diperlukannya suatu pelatihan Customer Service Excellence bagi karyawan RSCM yang berhubungan langsung dengan pasien maupun keluarga pasien. Seperti dalam fokus business lainnya, customer adalah orangorang, baik yang menikmati peningkatan status berdasarkan potensi mereka untuk membeli barang atau jasa (Torpie, 2014)

Modul kedua adalah dibuatnya tahapan role play dan latihan praktik untuk melatih ketrampilan (skill) praktik karyawan serta keberanian dalam mempraktikan pelayanan prima. Dari dua modul dan materi pengabdian yang telah dilakukan maka secara khusus dapat dibuat pernyatanyaan bahwa tujuan pengabdian kepada masyarakat ialah membekali para karyawan RSCM Kirana dengan pengetahuan mengenai layanan prima yang mencakup customer 
service, kepuasan customer, komunikasi verbal dan non-verbal, ketrampilan mendengarkan dan mengatasi customer yang sulit, serta memberikan tips dalam kepercayaan diri saat berkomunikasi dengan pasien atau keluarga pasien.

Modul kedua diambil dari beberapa literatur yang menjelaskan tentang skill karyawan Menurut Birkett, keterampilan kognitif mencakup keterampilan teknis - penerapan pengetahuan teknis, beberapa keahlian; keterampilan analitis / konstruktif identifikasi masalah dan pengembangan solusi; dan keterampilan apresiatif mengevaluasi situasi yang rumit dan membuat penilaian yang kreatif dan kompleks. Perilaku keterampilan meliputi: keterampilan pribadi bagaimana seseorang merespons dan menangani berbagai situasi; keterampilan interpersonal mengamankan hasil melalui hubungan interpersonal (Chopra, 2014)

Mutu pelayanan yang baik tidak hanya diukur dari kemewahan fasilitas, kelengkapan teknologi dan penampilan fisik akan tetapi dari sikap dan perilaku karyawan harus mencerminkan profesionalisme dan mempunyai komitmen tinggi. (Supartiningsih, 2017) Sehingga nantinya dengan pelatihan ini, dapat memberikan bekal

Dengan pelatihan ini diharapakan dapat menjadikan pelayanan RS Kirana dapat menerapkan apa yang menjadi misi rumah sakit yakni: Service Quality, Customer Value dan Customer Satisfaction (Surydana, 2017).

\section{Metode Penelitian}

Kegiatan pengabdian kepada masyarakat ini dilaksanakan oleh tim dosen dari LSPR dibantu oleh mahasiswa. Metode yang digunakan dalam pengabdian kepada masyarakat ialah dengan metode presentasi dan praktik (role play). Metode presentasi bertujuan untuk memberikan pembekalan kepada peserta seputar pengetahuan mengenai pelayanan prima (excellent service), menjelaskan mengenai konsekuensi dari tindakan yang tidak melayani kepada customer serta dampak positif dari layanan prima.

Pelaksanaan praktik melakukan peran (role play) dilakukan setelah para peserta dibekali dengan pengetuhan tentang layanan prima. Tujuan dari menjalankan peran (role play) agar peserta pelatihan dapat mempraktikan langsung pengetahuan yang didapat dari metode presentasi. Selama praktik para peserta dievaluasi oleh pelatih (trainer). Hasil evaluasi kemudian disampaikan kepada peserta mengenai area mana yang masih perlu diperbaiki dalam melayani pasien atau keluarga pasien yang membutuhkan layanan dari karyawan rumah sakit.

Adapun peserta pelatihan berjumlah 120 orang, terdiri para karyawan RSCM Kirana seperti petugas keamanan (Satpam), bagian penerimaan (receptionist), para perawat, bagian penerimaan uang atau kasir dan karyawan yang berhubungan langsung dengan pasien atau keluarga pasien yang melaksanakan pelayanan ke customer.

\section{Kegiatan Pelatihan}

1. Tahap pertama: registrasi peserta oleh pihak mitra RSCM Kirana. Melakukan re-registrasi di saat pelaksanaan pelatihan.

2. Tahap kedua: pelaksanaan pelatihan yang dijadwalkan oleh pihak RSCM Kirana dan dilakukan oleh tim dosen LSPR 
dengan peserta karyawan RSCM Kirana.

3. Tahap Ketiga: pelatihan materi, tanya jawab dengan peserta, praktik berdasarkan materi, role play dari kasus yang diberikan.

4. Tahap keempat: evaluasi dari TIM pengajar LSPR, dan Perwakilan Manajemen RSCM Kirana.

5. Tahap kelima: pemberian sertifikat oleh pihak LSPR

\section{Pelaksanaan Kegiatan}

Pelaksanaan kegiatan pelatihan dibagi menjadi dua tahap yaitu:

1. Tahap pertama: pelaksanaan pelatihan berupa penjelasan materi dari pelatihan kepada peserta sebanyak 30 orang tiap harinya selama 4 hari dengan total peserta 120 orang.

2. Tahap kedua: para peserta pelatihan diminta untuk memainkan peran (role play) dan memberikan solusi dalam simulasi kasus yang diberikan oleh pelatih (trainer).

\section{Materi Kegiatan}

Modul pelatihan Customer Service Excellence dibuat berdasarkan referensi yang berkaitan dengan layanan prima (Service Excellence). Sedangkan materi role play diperoleh dari referensi kasus yang terjadi pada rumah sakit. Berikut ini materi yang disampaikan sebagai berikut:

Materi pelatihan diawali dengan pengenal mengenai apa itu layanan kepada customer dengan ditampilkan video suasana kegiatan di rumah sakit, seperti pada Gambar 2.

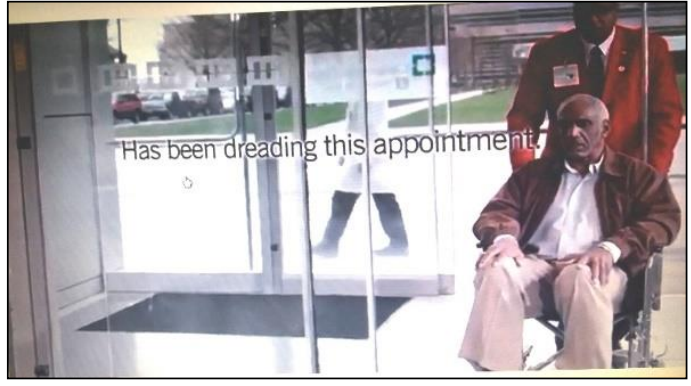

Sumber: www.youtube.com

Gambar 2. Pemutaran video dalam tahapan pelaksanaan pelatihan

Dalam video yang diputarkan tersebut menggambarkan keadaan suatu rumah sakit yang meliputi kunjungan pasien ke rumah sakit, kondisi pasien yang dirawat, kondisi pegawai yang mepunyai masalah dan lain-lain. Ilustrasi tersebut bertujuan agar para peserta menyadari bahwa betapa pentingnya melihat kondisi pasien dan yang membutuhkan layanan yang prima dari pihak rumah sakit.

Tahap berikutnya para peserta diberikan pengetahuan mengenai apa yang dimaksud dengan Customer Service, siapa saja yang termasuk customer dan harapan customer dalam hal ini pasien terhadap layanan rumah sakit. Bagaimana membuat harapan pasien menjadi kenyataan sehingga tercapai yang dinamakan kepuasan customer. Salah satu indikator dari kepuasan pasien ialah jika mereka bahagia akan layanan yang diberikan rumah sakit baik itu dari layanan medis maupun non medis.

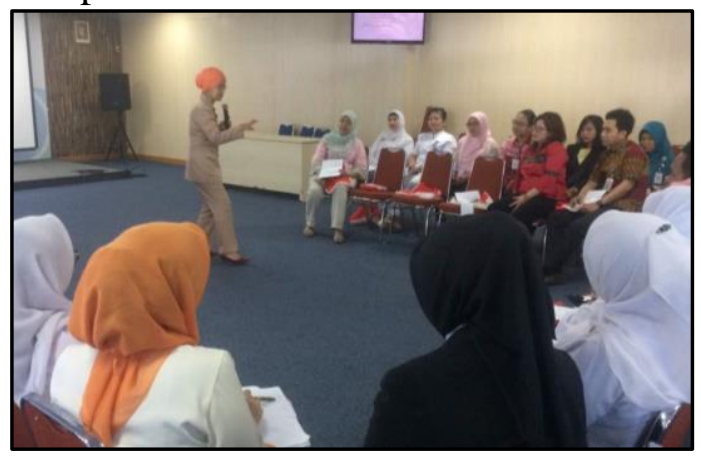




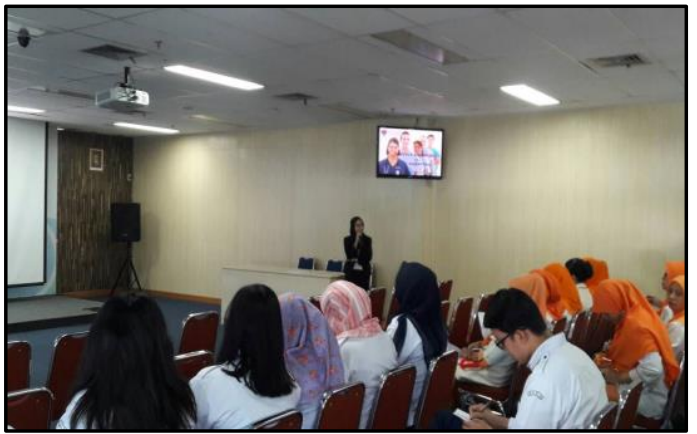

Gambar 3. Pemaparan Materi

Customer Service

\section{Tahapan Pelaksanaan Pelatihan}

Materi berikut yang disampaikan oleh instruktur ialah komunikasi. Komunikasi yang dilakukan oleh pihak rumah sakit kepada pasien ataupun keluarganya berupa komunikasi verbal maupun non-verbal. Komunikasi verbal terdiri dari lisan maupun tertulis. Adapun komunikasi non-verbal dapat berupa bahasa tubuh (body language), ekspresi wajah (facial expression), nada bicara, baju yang digunakan, perlengkapan asesori dan lain-lain. Ketrampilan mendengarkan (listening skills) kemauan pasien ataupun keluarga pasien juga termasuk yang diajarkan dalam pelatihan ini. Kemampuan ini dibutuhkan juga dalam menghadapi pasien ataupun keluarga pasien yang sulit dalam arti banyak menuntut.

Tahap terakhir pelatihan ialah mempraktikan semua pengetahuan yang telah diberikan oleh trainer kepada peserta. Peserta dibagi kelompok yang masing-masing kelompok diberikan kasus sesuai dengan yang terjadi di RS untuk kemudian para peserta diberikan waktu untuk membahas per kelompok dan diperagakan di depan peserta lainnya. Instruktur atau trainer melakukan evaluasi atas peragaan atau simulasi dari kelompok yang mempresentasikan di depan peserta lainnya. Saran atas hasil evaluasi diberikan oleh trainer kepada para peserta untuk dapat diperbaiki dalam pelaksanaan tugas sehari-hari.
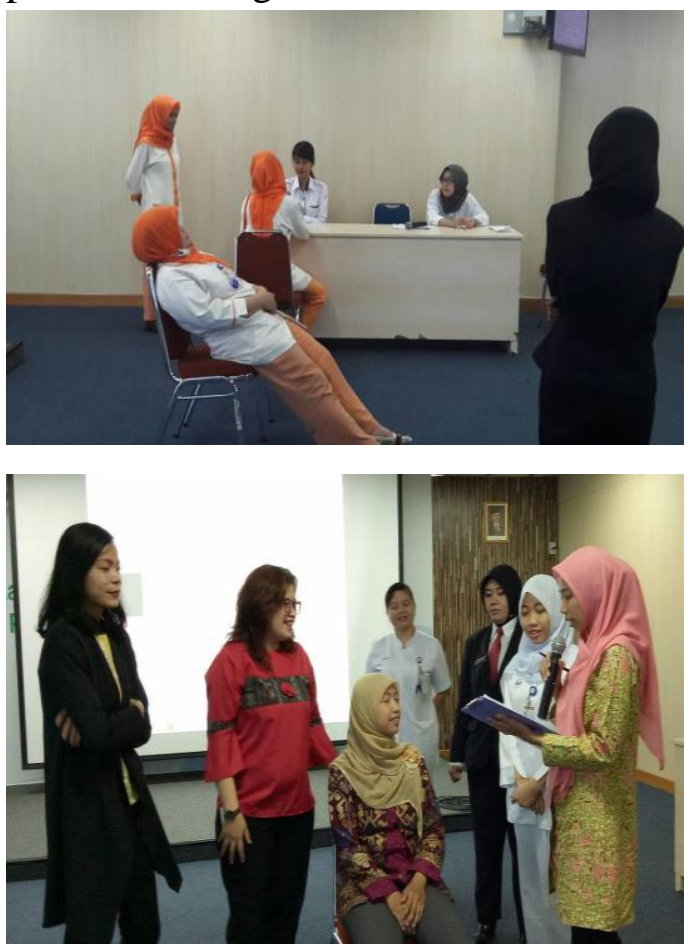

Gambar 4. Tahap Role play dalam tahap pelaksanaan pelatihan

\section{Hasil dan Pembahasan}

Dari hasil pelatihan menunjukan adanya perubahan yang cukup signifikan pada karyawan RSCM Kirana sebagai mitra setelah mendapatkan training atau pelatihan customer service excelent. Dua aspek yang menjadi point pelatihan yaitu pengetahuan dengan pemantaban materi ajar dan keterampilan dengan memberikan kasus dan role play menjadikan karyawan mengenal dan mengetahui cara berkomunikasi dengan customer.

Pada aspek pertama, dibagi lagi menjadi dua sub pelatihan yaitu materi komunikasi verbal dan komunikasi nonverbal pada saat melaksanakan pelayanan kepada customer. Awal dari pelatihan ini, karyawan dipotret terlebih dahulu bagaimana pengetahuan awal 
sebelum menerima pelatihan dan sesudah menerima pelatihan. Didapat hasil kedalam 3 dimensi pengukuran Tabel 1.

Tabel 1. Pre \&Post Test Training pada aspek Pengetahuan

\begin{tabular}{|c|c|c|}
\hline $\begin{array}{l}\text { Dimensi } \\
\text { Pengukuran }\end{array}$ & $\begin{array}{l}\text { Sebelum } \\
\text { Pelatihan }\end{array}$ & $\begin{array}{l}\text { Sesudah } \\
\text { Pelatihan }\end{array}$ \\
\hline $\begin{array}{l}\text { Pertanyaan } \\
\text { pada Konsep } \\
\text { Customer } \\
\text { Service }\end{array}$ & $\begin{array}{l}<\quad 30 \% \\
\text { Jawaban } \\
\text { Benar }\end{array}$ & $\begin{array}{l}60-80 \% \\
\text { Jawaban } \\
\text { benar }\end{array}$ \\
\hline $\begin{array}{l}\text { Pertanyaan } \\
\text { pada Teknik } \\
\text { Komunikasi } \\
\text { Verbal }\end{array}$ & $\begin{array}{l}<\quad 60 \% \\
\text { Jawaban } \\
\text { Benar }\end{array}$ & $\begin{array}{l}80-90 \% \\
\text { Jawaban } \\
\text { benar }\end{array}$ \\
\hline $\begin{array}{l}\text { Pertanyaan } \\
\text { pada Teknik } \\
\text { Komunikasi } \\
\text { Non Verbal }\end{array}$ & $\begin{array}{l}<\quad 55 \\
\text { Jawaban } \\
\text { Benar }\end{array}$ & $\begin{array}{l}85 \% \\
\text { Jawaban } \\
\text { benar }\end{array}$ \\
\hline
\end{tabular}

Data : Questioner dari 120 Orang

Dari tabel 1 hasil evaluasi menggambarkan adanya perubahan pada aspek pengetahuan, dimana sebelum diberikan pelatihan karyawan RSCM kirana, mayoritas masih awam dalam teknik komunikasi dan istilah konsep customer service. Setelah dilakukan pelatihan khususnya dalam sesi diskusi tanya jawab, mereka menyampaikan bahwa adanya penambahan informasi dan pengetahuan seputar customer service excellence dan terbukti ketika disebarkan kuesioner pemahaman pasca pelatihan adanya peningkatan jawaban yang benar.

Sedangkan pada aspek kedua, yaitu aspek keterampilan juga terlihat adanya peningkatan pada beberapa dimensi komunikasi non-verbal yang dijabarkan berdasarkan hasil wawancara dan observasi Tabel 2.

Dari data Tabel 2. juga menunjukan bahwa hasil pelatihan keterampilan mampu memberikan peningkatan dan perubahan pada karyawan RSCM Kirana, dalam aspek komunikasi non verbal kepada customer. Perubahan juga nampak pada saat role play, yang tadinya masih kaku, dengan tips komunikasi mereka mampu menjadi lebih luwes dalam bersikap dan membangun kepercayaan diri. Salah satu controh konkrit ketika mereka belum merasa percaya diri, ketika diberikan cara menegur, menyapa, menghadapi pertanyaan dan keluhan mereka lebih merasa percaya diri dan mau menjawab dan tidak menghindar dari customer.

Selain itu dari beberapa soal kasus yang diberikan, mereka mampu mengembangkan inisiatif dalam menghadapi customer, hal ini juga terlihat dari hasil pelatihan Tabel 3

Beberapa hal yang utama, terlihat karyawan RSCM dari hasil pelatihan ini juga sudah mulai mampu menciptakan moment of truth dan impression perusahaan, mereka meskipun dengan standar minimum, sudah mampu merepresentasikan identitas perusahaan seperti senyum, sapa, ramah dan komunikatif.

Meskipun demikian dari hasil pelatihan ini, juga terlihat bahwa peran perusahaan dalam menciptakan iklim komunikasi yang baik antara karyawan dan customer perlu dirumuskan dan di kelola dengan baik. Misalnya masih perlu adanya panduan dalam komunikasi efektif antara karyawan dan customer, bentuk komunikasi seperti apa yang perlu di tekankan kepada karyawan agar sesuai dengan visi misi perusahaan, adanya konsistensi pelatihan karena setiap level divisi akan mempunya permasalah komunikasi yang berbeda. Sehingga Mitra dalam hal ini RSCM Kirana masih perlu membenahi dari sistem kinerja karyawan dalam lingkup customer service excellence. 
Tabel 2. Pre \&Post Observasi Training pada aspek Keterampilan

\begin{tabular}{|c|c|c|}
\hline $\begin{array}{c}\text { Dimensi } \\
\text { pengamatan }\end{array}$ & Sebelum Pelatihan & Sesudah Pelatihan \\
\hline $\begin{array}{l}\text { Percaya } \\
\text { Diri }\end{array}$ & $\begin{array}{l}\text { 1. Sebagian besar staff kurang berani } \\
\text { menegur customer terlebih dahulu, } \\
\text { 2. Cenderung pasif, } \\
\text { 3. Tidak berani menjawab, } \\
\text { 4. Melempar ke beberapa staf lain } \\
\text { atau beberapa divisi. }\end{array}$ & $\begin{array}{l}\text { 1. Mau menyapa customer dengan } \\
\text { sapaan yang baik. } \\
\text { 2. Berani menjawab pertanyaan atau } \\
\text { keluhan customer dengan standar } \\
\text { informasi yang ditetapkan. }\end{array}$ \\
\hline $\begin{array}{l}\text { Pemilihan } \\
\text { kata pada } \\
\text { saat } \\
\text { melayani } \\
\text { cutomer }\end{array}$ & $\begin{array}{l}\text { 1. Menggunakan bahasa Informal } \\
\text { 2. Menggunakan Kata Tidak tahu } \\
\text { 3. Tidak mengikuti standar } \\
\text { ucapan/sapaan untuk di front } \\
\text { office }\end{array}$ & $\begin{array}{l}\text { 1. Menggunakan bahasa yang sopan dan } \\
\text { formal. } \\
\text { 2. Memastikan dan konfirmasi terlebih } \\
\text { dahulu sebelum menjawab customer. } \\
\text { 3. Mengacu pada sapaan standar } \\
\text { perusahaan. }\end{array}$ \\
\hline $\begin{array}{l}\text { Mimik } \\
\text { wajah } \\
\text { (Facial } \\
\text { expression) }\end{array}$ & $\begin{array}{l}\text { 1. Kaku } \\
\text { 2. Datar } \\
\text { 3. Menunduk } \\
\text { 4. Memalingkan Wajah } \\
\text { 5. Kurang eye contact }\end{array}$ & $\begin{array}{l}\text { 1. Menjadi luwes } \\
\text { 2. Tersenyum } \\
\text { 3. Memberikan eye contact }\end{array}$ \\
\hline $\begin{array}{l}\text { Isyarat } \\
\text { (Gesture) }\end{array}$ & $\begin{array}{l}\text { 1. Kaku } \\
\text { 2. Judes } \\
\text { 3. Sambil berjalan ketika berbicara } \\
\text { dengan customer } \\
\text { 4. Cuek }\end{array}$ & $\begin{array}{l}\text { 1. Fokus dan gesture mengikuti arah } \\
\text { pertanyaan atau keluhan customer. } \\
\text { 2. Inisitaif untuk membantu }\end{array}$ \\
\hline
\end{tabular}

Data: Olahan wawancara dan hasil observasi

Tabel 3. Pre\&Post Observasi

\begin{tabular}{|c|c|c|}
\hline Penilaian & Sebelum Pelatihan & Sesudah Pelatihan \\
\hline $\begin{array}{l}\text { Inisiatif } \\
\text { Memberikan } \\
\text { Informasi }\end{array}$ & $\begin{array}{l}\text { 1. } \text { Tidak peduli } \\
\text { 2. Mau berkomunikasi } \\
\text { pada diketahui saja } \\
\text { 3. Berbelit-belit } \\
\text { 4. }\end{array}$ & $\begin{array}{l}\text { 1. Mereka melihat sekitar dan } \\
\text { inisitaf dalam memberikan } \\
\text { infomasi. } \\
\text { 2. Informasi sudah berdasarkan } \\
\text { alur SOP dan inisitaif } \\
\text { berdasarkan alur kerja. } \\
\text { 3. Informasi Sudah runut dan } \\
\text { tidak di oper-oper ke divisi } \\
\text { lain, karyawan berinisiatif } \\
\text { untuk mefolow up divisi lain } \\
\text { sehingga, jika sudah jelas baru } \\
\text { disampaikan ke customer. }\end{array}$ \\
\hline $\begin{array}{l}\text { Inisiatif } \\
\text { Menangani } \\
\text { keluhan }\end{array}$ & $\begin{array}{l}\text { 1. Cenderung takut } \\
\text { menghadapin komplain. } \\
\text { 2. Beberapa staf, } \\
\text { cenderung defense jika } \\
\text { ada komplain. } \\
\text { 3. Bingung tidak tahu } \\
\text { harus melapor atau apa } \\
\text { yg harus dilakukan }\end{array}$ & $\begin{array}{l}\text { 1. Berinisiatif kordinasi dengan } \\
\text { divisi lain pada saat menerima } \\
\text { komplain. } \\
\text { 2. Inisiatif untuk mencatat dan } \\
\text { membuat laporan komplain. } \\
\text { 3. Berinisiatif dalam menjawab } \\
\text { /merespon komplain. }\end{array}$ \\
\hline
\end{tabular}

Data: Olahan hasil observasi 


\section{Kesimpulan dan Saran}

Dari kegiatan pengabdian masyarakat yang telah dilakukan dapat disimpulkan beberapa hal terkait dengan pentingnya komunikasi, khususnya dalam aspek customer service excellence:

1. Mitra dalam hal ini perusahaan jasa, rumah sakit RSCM Kirana, erat kaitannya dengan pelayanan, tidak hanya pelayanan medis, namun juga pelayanan non medis. Pelayanan non medis berkaitan dengan kegiatan administrasi dan komunikasi, dalam hal ini komunikasi diperlukan dalam menjelaskan alur dan prosedur rumah sakit kepada pasien. Dengan komunikasi efektif dapat membuat pasien merasa cepat direspon, ditangani dan diarahkan dengan baik sehingga pelayanan prima akan sangat dirasakan oleh customer.

2. Pelatihan ini menujukan bahwa customer service excellence harus dibangun dari dua bentuk komunikasi yaitu komunikasi verbal dan non verbal. Komunikasi verbal bisa dilihat efektifitas berkomunikasi, alur, pemilihan bahasa dll, sedangkan komunikasi non verbal bisa dalam bentuk mimik, bahasa tubuh hingga rasa percaya diri dalam menghadapi pasien.

3. Pengalaman dalam menghadapi customer juga menjadi modal penting, dan pelatihan ini juga memberikan kesempatan staf untuk membangun inisiatif karyawan dalam mendapatkan kasus atau persoalan seputar customer service excellence.
4. Pelatihan yang diberikan dengan mencakup pada dua aspek, pengetahuan dan keterampilan dirasa dapat membantu mitra dalam meningkatkan kinerja karyawan. Dari data pretraining juga masih menunjukan bahwa karyawan masih awam dengan beberapa konsep customer service excellence dalam aspek pengetahuan.

Beberapa rekomendasi berdasarkan hasil evaluasi yang telah dilakukan diantara dapat disampaikan kedalam beberapa point sebagai berikut kepada Mitra:

1. Untuk masa mendatang sebelum menempatkan orang pada posisi yang berkaitan dengan customer service, maka RSCM Kirana perlu membuat pelatihan atau diklat yang membekali calon karyawan tentang pengetahuan dan ketrampilan "customer service excelence". Hal ini untuk mengantisipasi adanya kegagapan kerja, dari karyawan RSCM Kirana sebelum diterjunkan pada pekerjaan yang sebenarnya.

2. Jika kondisi telah terjadi, maka perlu dilakukan sistem observasi kinerja karyawan secara berkala, dari atasan untuk menilai apakah perlu adanya pelatihan tambahan berdasarkan tingkatan atau level customer service yang diperlukan. Hal ini disebabkan setiap divisi memungkinkan level ketrampilan customer service yang berbeda.

3. Jika ada kondisi dimana satu orang karyawan tidak juga mampu menciptakan iklim customer service excellence, karena adanya ketidakcocokan 
dalam penempatan posisi front liner atau service, maka karyawan tersebut dapat ditempatkan pada posisi back office.

4. Perlunya dibuat SOP dan panduan komunikasi pelayanan, sehingga karyawan dapat membaca dan mengacu pada layanan standar yang ditetapkan oleh RSCM Kirana.

5. Dari hasil pengabdian masyarakat untuk mengukur apakah karyawan sudah menyerap pengetahuan dan menerapkan dipekerjaan pasca mengikuti training, dapat dilakukan uji kompetensi kepada karyawan front liner.

\section{Ucapan Terima Kasih}

Tim pelaksana Pengabdian kepada Masyarakat (PkM) menyampaikan terima kasih kepada pihak Lembaga Penelitian dan Pengabdian Masyarakat (LPPM) LSPR yang telah membantu pendanaan dalam pelaksanaan program ini. Selain itu tim pelaksana mengucapkan terima kasih kepada RSCM Kirana atas kerjasamanya sehingga PkM dapat terlaksana dengan baik.

\section{Daftar Pustaka}

Carlzon J. 1987. Moments of Truth. Massachusetts: Ballinger Publishing. Chopra, K. 2014. Empirical study on role of customer service in delivering satisfaction at branded retail outlets in Pune. Symbiosis Institute of Management Studies Annual Research Conference (pp. 239-246). Elsevier - Science Direct.
Dhuhaniyati, I. A. 2012. Implikasi Pelayanan Prima (Service Excellence) Dan Paket Agenda Reformasi Layanan Kesehatan : Pelajaran Menarik Dari Singapura Dan Malaysia Bagi Indonesia. Jurnal Reformasi, Volume 2, Nomor 2, 109115.

Figen Yeilada, E. D. 2010. Health care service quality: A comparison of public and private hospitals. African Journal of Business Management Vol. 4, 962-971.

Kuntjoro, T.H. D. 2007. Standard Pelayanan Minimal Rumah Sakit Sebagai Persyaratan Badan Minimal Umum dan Sarana Peningkatan Kinerja. Journal Manajemen Pelayanan Kesehatan, 3-10.

Pusat Data PERSI. 2013. RSCM Kirana,

Pusat Oftamologi Terbaik di Indonesia Juga Asia Pasifik.

(http://www.pdpersi.co.id/content/ne ws.php?catid $=2 \& \operatorname{mid}=5 \&$ nid $=1261$ ) diunduh tanggal 1 Juli 2018.

Supartiningsih, S. 2017. Kualitas Pelayanan Kepuasan Pasien Rumah Sakit: Kasus Pada Pasien Rawat Jalan. Jurnal Medicoeticolegal dan Manajemen Rumah Sakit, 9-15.

Surydana, L. 2017. Service Quality, Customer Value and Patient Satisfaction on Public Hospital in Bandung District, Indonesia. International Review of Management and Marketing, 187192.

Torpie, K. 2014. Customer service vs. Patient care. Patient Experience Journal Vol. 1 Issue 2, 6-8.

Zeithaml, VA., Parasuraman A \& Berry, L.L 1990. Delivering Quality Service. New York: The Free Press. 